\title{
Personalized Learning: Current Status and Potential
}

\author{
David Nandigam \\ Unitec Institute of Technology \\ Auckland, New Zealand
}

\author{
Sreenivas Sremath Tirumala \\ Unitec Institute of Technology \\ Auckland, New Zealand
}

\author{
Nilufar Baghaei \\ Unitec Institute of Technology \\ Auckland, New Zealand
}

\begin{abstract}
The term personalized learning has proliferated over recent years especially with the advancement of several educational technologies, conceptual frameworks and mobile and wireless internet technologies. The aim of this paper is to identify an acceptable personalized learning paradigm for educators. A detailed literature review on various aspects of personalized learning is also presented. Eleven participants with moderate to highly-experienced in teaching across eight countries took part for this study. The data is collected via LinkedIn collaborative participation eliminating the possibility of bias towards a particular outcome. This provides both theoretical and empirical aspects of the topic in question. The data collected from the group discussions was analyzed using content analysis techniques and the issues raised by the participants were categorized into emerging themes. This paper concludes with acknowledging the necessity of good combination of teaching and technology for a successful personalized learning paradigm.
\end{abstract}

Index terms - Personalized learning, e-learning, Customized learning; Individualized learning

\section{INTRODUCTION}

The basic premise of Personalized Learning (PL) is the belief that each student is unique and learns in different ways. It has been suggested that personalized learning is originated from Howard Gardners theory of multiple intelligences [1] [2]. Thus, the variables for personalized learning include individual pupils interests, their needs and abilities, and the identification of the best learning style for each pupil [3]. Personalized Learning strategies have a number of potential advantages over traditional learning methods and on-the-job training and they are consistent with constructivist learning theories [4], [5], which emphasize that learning is active and knowledge is built on top of own experiences.

It is the objective of this study, therefore, to present a coherent framework for an on-the-fly personalized learning and to provide the most acceptable personalized learning paradigm for educators and practitioners. This research was carried out using the platform of Higher Education Teaching and Learning (HETL), a LinkedIn discussion group. The goal of the discussion group, HETL is to improve educational outcomes in higher education by creating new knowledge and advancing the scholarship and practice of teaching and learning. HETL members represent all disciplines, functions, and levels within education. HETL is open to education professionals from all institutional types and missions. This diversity allows HETL to create a global perspective on teaching and learning. As such, the participants in this paper come from eight countries with moderate to highlyexperienced in teaching and training. (see Appendix 1). Thus the study is a holistic overview of personalized learning with participation from real practitioners coupled with reference to current learning theory and state-of-the-art techniques that justify personalized learning as a viable model.

The structure of the paper is as follows. Section 2 paints a picture of personalized learning against the prescriptions of educational policy coupled with the the perspectives of the classroom practitioners within the context of the existing learning theories. Section 3 highlights technological developments pertinent to this study. It summarises the developments in the areas of mobility, collaboration, gamebased, context awareness and augmented reality. Section 4 presents a discussion of the implications of the framework and some insights into future work, and then the conclusion is presented as Section 5 .

\section{TheORY AND PRACTICE}

Personalized Learning varies in definition in the contexts in which it is being applied today. In order to come to terms with both the theoretical and empirical aspects of personalized Learning, it is necessary to consider, to begin with, what has been written in the education policy documents as well as the approaches that educational institutes or teachers adopt in their practice. Personalized Learning is viewed by policy makers as "shaping of students' learning activities and the curriculum/knowledge content that reflect the input and interests of students" [6]. By this it is assumed that students can understand how they learn, own and drive their learning and are co-designers of the curriculum and their learning environment. It also implies that student learning needs, interests, and capability determine the pace of learning. This idea resonates with what practitioners seem to feel as one respondent remarks: "By definition personalisation means wide diversity in the components that go into learning and how they are combined"

Another respondent remarks: "Maybe personalisation has to come through how the student engages with content and the outcomes they produce from it rather than from the media through which knowledge and skills development is channelled."

In this environment, all the resources are made available for learning. They include teachers, parents, peers, technology, time, and learning spaces with the view that they will be used flexibly to meet individual student learning needs. It also, however, establishes the fact, as one respondent rightly identifies, "Personalized learning needs a degree of 
compromise and learner initiative which has too often been missing."

It is, therefore, important that each learner realizes their individual characteristics and needs such as different prior knowledge, cognitive abilities and learning styles. These individual differences affect the learning processes and are the reason why some learners find it easy to learn in aparticular subject of study, whereas others find the same subject difficult [7].

Personalized learning can involve different levels in the educational process, including personalization of the curriculum, the courses, as well as the support provided within the courses. Furthermore, personalized learning can take place in traditional (face-to-face) learning settings as well as in technology-enhanced learning settings. In traditional approach, personalized learning requires a small number of learners per teacher. The small number of learners makes it possible for teachers to tailor their lessons, activities, and support, respectively. This gives learners more choices in the curriculum programs, allows parental involvement in education (if learners are children), affords student-driven learning, and involves learners in the decision making processes. A respondent remarks:

"I've taught at multiple levels so one example of personalized instruction is for high school math. Within a whole group plan for objective setting, methodology and evaluation on a topic, knowing intimately the progress of each student, and understanding achievement expectations of student and family, I extended or contracted requirements for each student individually or in small groups."

The advantage of employing technology, however, is that students can make use the content and become experts on par with their teacher. They can become experts on specific content areas and even create content. Personalising learning challenges educators to think about what new resources may be needed to support learning, and how learners can access them. Some of these resources may include those that have not traditionally been thought of as part of the education system. But one has to be mindful of the limitations too as one of the respondents identifies: An app which is ideal for one learner will be loathed by another and no institution has the resources to provide a different one for every single student or parade them in front of people until they pick one they like.

In spite of such limitations, much progress has been made in meeting the individual requirements of learners with the advancement of several educational technologies coupled with mobile and wireless internet technologies. The next section highlights some of the developments pertinent to the study.

\section{TeCHnOlOgY-ENHANCED PERSONALIZED LEARNING}

The use of technology in education opened up new possibilities for providing personalized learning to learners and significantly enhanced the potential of personalized learning. Through the development and usage of learning systems, large numbers of learners in a class have been able to use and benefit from personalized learning as evident in literature [8].

In most of these studies, an intelligent learning system is able to identify the characteristics of individual learners such as prior knowledge, learning styles, cognitive abilities, learning interests, learning goals and motivation [9] from the feedback collected from the individuals. The knowledge thus realized allows the system for imparting personalized learning [10]. In addition, the system is able to monitor individual behaviour and their actions for further honing its knowledge of the individual.

Another aspect where technology has been able to facilitate personalized learning is the individualization of curriculum. Such a curriculum is the result of the system considering various factors of learners in order to generate the most suitable curricula as well as the best sequence of learning items for each learner.

Most of the current research on personalized learning is strongly related to technology-enhanced learning, enabling learning systems to provide personalized learning which otherwise is not feasible given the traditional classroom constraints. One of the participants of the current study remarks saying: "If I wouldn't use and point the students into the direction of quality sources online or in books ... I wouldn't be able to free up enough time to personalize their processes ... if they wouldn't ask each other for advice or tips through Facebook and answer those before I have to (I do check if the right advice or tips are given) ... again I wouldn't have enough time to really engage with the students in that very personal way ... so in that sense technology does help."

On the other hand, a significant body of research is underway into integrating more complex aspects of personalized learning such as user modeling into learning systems. Such systems simulate the behaviour of human teachers [11] with a view to provide an experience similar to personal tutoring without human intervention. They typically provides an environment in which students can practice their skills as well as problem-solving .

Knowledge-based systems such as Thermo-Tutor [12] collect information about the students actions and develop a student model based on the learner-activity. Then they adapt the instructional activities to suit the skills and abilities of each individual student. The adaptation is done mostly in terms of providing feedback, selecting or generating problems at the right level of complexity, or deciding the topics to be taught. Thermo-Tutor is designed to complement traditional courses with a number of problem solving opportunities based on the concepts taught in lectures. Students have the choice to select problems to work on, and submit their solutions for feedback anytime and anywhere.

Yet again, the practitioners feel the necessity of learner becoming the owner of their learning. One of the respondents says:"Personalized learning requires a developed sense of taking responsibility for one's learning and a recognition that it takes effort on the part of you as a student rather than the expectation which endured too long that institutions would analyse you so well that what they provided to you was 
perfect for you, nothing superfluous, delivered at precisely the right time and so on."

Some of the practical constraints notwithstanding, it is identified that personalized learning with other pedagogical models such as mobile learning, ubiquitous learning, gamebased learning, collaborative learning etc. has high potential to enhance the respective model by improving the learning progress and outcome of learners as outlined below.

\section{A. Mobility}

The use of mobile wireless devices afford personalized learning while on the move [13] and the rise of these technologies provide positive pedagogical affordances. More over, this mobility enables personalized learning in formal and informal settings by decreasing "the dependence on fixed locations for work and study, and consequently change the way we work and learn" [14].

Klopfer and Squire [15] highlight three factors of mobile learning, namely, "portability, social interactivity, context, and individuality". Out of these three, portability is the factor that makes other technological attributes such as individuality and interactivity possible. Thus the first generation of truly portable information has come integrated with many functions through these small, hand held electronic devices [14] such as smart-phones and PDAs.

Mobile devices have become more dynamic and pervasive with the recent technological innovations in social networking due to the rise of Web 2.0. As a result, the content is more personalized and also possible is the learning across contexts [16]. Brown [17] identified mobile learning as "an extension of personalized e-learning." Peters [14] also stated that it was a subset of e-learning, a step toward making the educational process "just in time, just enough and just for me."

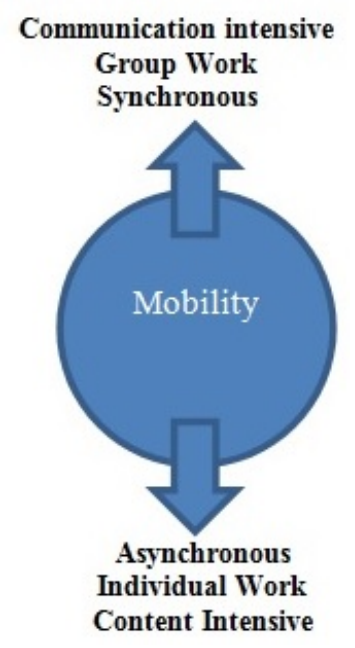

Fig. 1. Mobility Affordances

As indicated by Fig 1, mobile technology has two personalizable attributes: (1) to increase an individuals organizational skills and self-regulative (or self-directed) learning ability, and (2) communication, collaboration, and knowledge construction. This shows that, students can consume and create information both collectively and individually [18].

\section{B. Collaboration}

Research provides compelling evidence on the importance of working towards student collaboration in the learning process to a large extent [19]. Thankfully, the evolution of Web 2.0 based social technologies promote a number of useful learning avenues through informal conversation, reflexive dialogue and collaborative content generation as well as providing access to a wide variety of ideas and representations. Interestingly the majority of these tools shift control to the learner in number of different ways including promoting learner autonomy and engagement in social networks across physical, geographic, institutional and organizational settings. However, in order for an individual's learning to come to fruition, they not only need to be able to choose relevant tools and content from what is available, but also to have access to the necessary scaffolding to support their learning. Following is an example from one of the respondents: "For some strong students on or above grade level in a failing urban school, I used education psychology and Web 2.0 instructional technology to stretch performance. Best students led small online groups, were available for questions, checked answers for class practice while focusing on homework. Average students got large online group instruction on methods to meet objectives, joined smaller groups for practice, and learned the procedures checking answers and asking best students questions along the way, in lieu of teacher availability. I had no teacher aides at all. Poor students had steps explained while working through sample text problems with written discussion available. Alternate methods might be shown the slower students with more tangible materials and hands on teaching."

\section{Game-based}

Increasing interest in game-based learning established great opportunities for personalization of learning. Gamebased personalized learning is consistent with constructivist learning theories [4], which emphasize that learning is active and knowledge is built on top of one's own experiences. Personalized games include tolerance and encouragement of risk within a safe environment [20], thus promoting and encouraging experimentation instead of passive learning [21] [22]. They can support personalized learning that is active, experiential, situation based, problem and inquiry-based, and they provide immediate feedback. They also involve communities of practice which provide collaborative support to learners [23]. Evidence for their efficacy as educational tools is growing. A number of research studies find that serious games, compared with more traditional learning methods, improve learning and retention at a higher rate [24] [25] [26]. One of the respondents testifies thus: "Accelerated students were assigned computer exercises/games to practice with minimal explanation and received students who finished early for extension of concepts on computer under peer supervision. Alternative class support tasks were selected by students for the week to include textbook distribution, forms distribution, other routine tasks the group required. Grades including test results, classwork/homework production and 
related notes were posted weekly anonymously. My classes composed of students from grade level to primary school ability level were rated tops in achievement for many years. Even special ed students achieved remarkable results prompting many questions of me from their other teachers."

\section{Context awareness}

With the evolution of mobile technology there is a growing interest about context-aware learning in the research community over the last decade. Particularly the studies of Hwang [27] and others deal with the context-aware learning activities that use an algorithm for planning personalized learning paths such as the ones represented in mind-tools and concept maps.

For instance, a Personalized Context-Aware English vocabulary Learning system [28] is developed to help enhance learners' ability in using and practicing the language appropriate to the context where they are in. This application takes three variables into account. Based on the learner's location, their individual abilities and the time of the day, the system determines the kind of vocabulary the learner might need and serves the relevant content. For example, vocabulary related to Christmas is served if the date is 25 December, and the content related to food and drinks is served if the learner is in a restaurant.

The CLUE knowledge-awareness application [29] enables collaborative learning between learners. In order to facilitate the learning between two groups of distance learners, CLUE identifies the nearest learners and their knowledge about the subjects/topics that they are working on currently. The information thus gained is geographically displayed in a knowledge awareness map. This allows the learners to seek help from one another and leads them to find collaborative peers to work with to learn or study and solve problems.

Context-awareness is effectively used in Sharable Courseware Object Reference Model (SCORM) constructed by Wang et al. [30]. In this system, the intentions as well as the preferences of the learners are used as the basis for selecting relevant learning objects. SCORM (2003) became an international standard proposed by advanced distributed learning initiative (ADL) which has been widely used since then to solve the problems of sharing and reusing learning materials in different and incompatible formats of web-based learning systems..

\section{E. Augmented Reality $(A R)$}

AR uses a calculated field position and camera angle to impose a layer of virtual objects over the real-world background [31]. Learners can immerse themselves in the combined virtual and real-world scenes as well as interact with the virtual objects and access relevant information[32]. AR systems can be designed to provide students with personalized scaffolding and support and help them construct personal knowledge as they observe and experience realworld contexts [33] [34]. In recent years, AR has been applied to learning environments in an attempt to overcome drawbacks associated with traditional teaching environments. Some of these technologies have been shown to improve learning outcomes and learning motivation. The goal of many such systems is to provide learners with a friendly, interactive interface and rich, engaging media to stimulate intrinsic motivation and learning performance. The key advantages of AR in personalized learning include the following: (1) it helps stimulate learning intention through pursuing outdoor learning objectives, (2) AR technology provides learners with contextual information related to the outdoor learning environment, and (3) it enhances learner retention of teaching contents easily with the situated learning strategy [35].

Both Android and iPhone support AR in navigation features, providing users with personalized location-specific information. Images have a stronger impact on memory than text, thus layering supplementary images and information over the real world environment in the AR environment can promote knowledge retention [36].

Liarokapis et al. [37] proposed an interactive Multimedia Augmented Reality Interface for E-learning system and developed a user-friendly interface to explore the potential of $\mathrm{AR}$ in instruction by superimposing virtual multimedia content information in an AR tabletop environment. Matcha and Awang Rambli [38] investigated the potential of AR spaces to supply communication cues and promote collaboration in learning environments. Their empirical results indicated that AR techniques have significant potential to serve as a shared medium in personalized collaborative learning.

\section{DISCUSSION}

Considering the perspectives of the educationists as well as the current technological developments in the field, the paradigm of personalized learning can be interpreted as a continuum from teacher to students as well as individualized to participatory (see Fig. 2). Many such operational definitions have influenced it's evolution. According to a respondent "Personalized learning is really learner-centered learning where each of us are learners and at time even students are the teachers. If it is designed on research validated principles of learning, motivation, and development - how it is delivered is secondary. It is not about technology - that is merely one of many tools that may be needed in some cultures and contexts."

For this study, personalized learning is regarded as a single continuum that is initiated by teacher-mediation which then moves to a model that is technology driven. Personalized learning in its simplest form, therefore, is used to fill a psychological gap between teacher and learner and requires a definite structure and dialogue. However, the emerging communication technologies make it possible that the learning structures are built not only by the teacher or curriculum designer but also by collective learners themselves; and dialogue is also formed not only between the teacher and learners, but also between the learners. Communication through mobile phones and working in wikis are just a few examples of how learners build structure through dialogue [39]. Moore [40] calls this "inter-learner dialogue" because this kind of learner collaboration can make knowledge creation possible for variety of learning styles.

Structure and dialogue, previously regarded as being under the teacher's control, have come to be something that learners can better create for a much better outcome. In 
effect, every definition of personalized learning must include the interaction that learners can now have among themselves, for themselves and by themselves. It is, therefore, possible to regard learner-built dialogue and structure alone as a different dimension. Such a new dimension connotes "individual versus collective (or social)" activities by considering the importance of the social aspects of learning as well as newer forms of social technologies. This idea was formed by the influence of cultural-historical activity theory that Kang and Gyorke [41] proposed.

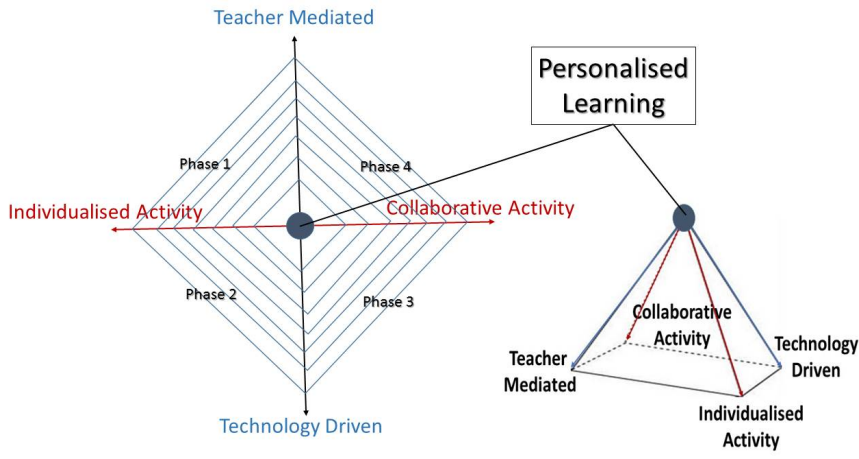

Fig. 2. Personalized Learning Paradigm

However, the role of the teacher is not diminished in any sense. As one respondent rightly points out, "The real problem is using technology to do what teachers naturally do very well - connecting with their students, motivating them to learn in a variety of ways that fit their interests and skills, and being real partners in the learning journey. Teachers either know what technologies are best or they know their students do and use them as expert teachers when the class needs to learn from their peers." As another respondent remarks, "Learning is not like online grocery shopping and as we know even that is never perfect. An app which is ideal for one learner will be loathed by another and no institution has the resources to provide a different one for every single student or parade them in front of people until they pick one they like."

On the other hand, there is this vice of technology misuse. For example, as one respondent points out, "I see technology becoming the 'babysitter' for babies through adult learners - too many institutions encourage teachers to use the latest and greatest program while completing their mountains of accountability paperwork. There is misuse from students point of view as well as one respondent points out."

Some educationists say doing this is more work and adds to their already overfull plate of responsibilities. However for those educators who have stayed the course and helped mentor students in research-validated ways to create learner and learning-centere environments, personalization is a natural outgrowth. The jobs of teaching and learning are in fact become easier because the responsibility is shared, and if students are allowed to establish classroom rules for what will and will not be used inappropriately in technology rich or poor environments - misuse of social media or other tools will disappear with peer pressure.

\section{CONCLUSION}

This study presents the data analysis from the reflections of the educationists on a LinkedIn focus-group relating to the individual personalized learning perspectives. Based on the analysis, a personalized learning paradigm has been evolved. From the study it appears that personalized learning spaces, resources and environments to be developed, supported and created through systematic design as well as by inclusion of both instructor and learner perspectives. As online learning has now become the global mode of learning, it is important that students develop reasonably high levels of digital skills to enable them to negotiate, interact and access resources independently [42]. Further more, the dispositions developed through engagement with Web 2.0 - i.e. communication, participation, networking, sharing, overlap with what are considered as essential 21 st-century learning and employability skills [43].

Nonetheless this study identifies the need for explicit scaffolding of essential skills for "the total dependence on software is a barrier to implementing personalized learning - although the right type of software can support the process if it is facilitated through a developmental process of blended learning (i.e. both class-based and web-based)"as one of the respondent remarks.

The challenges that educators now face are complex and multifaceted. They include the provision of suitable technologies that cultivate personalized learning, while promoting learner reflection and the development of generic competencies. The complexity is well represented by the comment of one respondent which reads, "There is also the issue of sense of ownership: that if academics are involved in something that it stops being cool."

Another respondent remarks: "We certainly need to alert students to the fact that socialising with friends is not learning and in fact eats into their time for learning." Hence, the study proposes the necessity of good combination of teaching and technology for a successful personalized learning paradigm and that is continuously adapted for each individual learner.

\section{APPENDIX}

TABLE I. PARTICIPANTS' DATA

\begin{tabular}{|l|l|l|}
\hline Participant & Expertise & Country \\
\hline 1 & Faculty at FIDM & Concordia University \\
2 & Founder Lifewide Education CiC & Betchworth, Surrey, United Kingdom \\
3 & Learning Communities in Higher Education & Brussels Area, Belgium \\
4 & Faculty Education Co-ordinator & Surrey, United Kingdom \\
5 & Professor of Commerce & Bardhaman, India \\
6 & Senior Research Scientist & Jacksonville, Florida Area Research \\
7 & Education Researcher & San Francisco Bay Area Research \\
8 & Education Management Consultant & University of Southern Denmark \\
9 & Founder at Global Digital University & Istanbul, Turkey \\
10 & Education Researcher & Charles Sturt University, Australia \\
11 & Trainer and Lecturer & Massey University, New Zealand. \\
\hline
\end{tabular}

\section{REFERENCES}

[1] G. H. (2004, Jun.) Tclass divisions: Who benefits from the personalised learning strategy of dividing school pupils into subsets.

[2] M. Johnson, "Personalised learning," New Economy, vol. 11, no. 4, pp. 224-228, 2004.

[3] T. L. Good and J. E. Brophy, Educational psychology: A realistic approach . Longman/Addison Wesley Longman, 1990. 
[4] J. R. Savery and T. M. Duffy, "Problem based learning: An instructional model and its constructivist framework," Educational technology, vol. 35, no. 5, pp. 31-38, 1995.

[5] A. Pritchard, Ways of learning: Learning theories and learning styles in the classroom. Routledge, 2013.

[6] C. Theobald, "Changing our behaviours as teachers in order to meet the needs of our culturally diverse students: a thesis presented in partial fulfilment of the requirements for the degree of master of education (teaching and learning) at massey university, new zealand," $\mathrm{Ph} . \mathrm{D}$. dissertation, Massey University, New Zealand, 2013.

[7] D. H. Jonassen and B. L. Grabowski, Handbook of individual differences learning and instruction. Routledge, 2012.

[8] S. Graf, "Adaptivity in learning management systems focussing on learning styles," Ph.D. dissertation, Vienna University of Technology, 2007.

[9] S. Graf, G. Yang, T.-C. Liu, D. Kinshuk et al., "Automatic, global and dynamic student modeling in a ubiquitous learning environment," Knowledge Management \& E-Learning: An International Journal (KM\&EL), vol. 1, no. 1, pp. 18-35, 2009.

[10] P. Brusilovsky, "Methods and techniques of adaptive hypermedia," User Modeling and User-Adapted Interaction, vol. 6, no. 2-3, pp. 87-129, 1996

[11] A. Mitrovic, B. Martin, and P. Suraweera, "Intelligent tutors for all: The constraint-based approach," IEEE Intelligent Systems, vol. 22, no. 4 , pp. $38-45,2007$.

[12] A. Mitrovic, C. Williamson, A. Bebbington, M. Mathews, P. Suraweera, B. Martin, D. Thomson, and J. Holland, "Thermotutor: An intelligent tutoring system for thermodynamics," in Global Engineering Education Conference (EDUCON), 2011 IEEE. IEEE, 2011, pp. 378-385.

[13] A. Kukulska-Hulme and J. Traxler, Mobile learning: A handbook for educators and trainers. Psychology Press, 2005.

[14] K. Peters, "m-learning: Positioning educators for a mobile, connected future," The International Review of Research in Open and Distance Learning, vol. 8, no. 2, 2007.

[15] E. Klopfer and K. Squire, "Environmental detectivesthe development of an augmented reality platform for environmental simulations," Educational Technology Research and Development, vol. 56, no. 2, pp. 203-228, 2008.

[16] K. Walker, "Introduction: Mapping the landscape of mobile learning," in Big issues in mobile learning: Report of a workshop by the kaleidoscope network of excellence mobile learning initiative. University of Nottingham, 2006.

[17] T. H. Brown, "Towards a model for m-learning in africa," International Journal on E-learning, vol. 4, no. 3, pp. 299-315, 2005.

[18] M. L. Koole, "A model for framing mobile learning," Mobile learning: Transforming the delivery of education and training, vol. 1, no. 2, pp. 25-47, 2009.

[19] V. Prain, P. Cox, C. Deed, J. Dorman, D. Edwards, C. Farrelly, M. Keeffe, V. Lovejoy, L. Mow, P. Sellings et al., "Personalised learning: lessons to be learnt," British Educational Research Journal, vol. 39, no. 4, pp. 654-676, 2013.

[20] I.B.M. (2007, Jun.) Virtual Worlds: Real Leaders. Online Games put the future of buisiness leadership on display.

[21] de Freitas S, "Emerging technologies for learning," Becta, Tech. Rep., February 2008.

[22] M. Kebritchi, A. Hirumi et al., "Examining the pedagogical foundations of modern educational computer games," Computers \& Education, vol. 51, no. 4, pp. 1729-1743, 2008.

[23] E. Boyle, T. M. Connolly, and T. Hainey, "The role of psychology in understanding the impact of computer games," Entertainment Computing, vol. 2, no. 2, pp. 69-74, 2011.

[24] D. Charles and M. McAlister, "Integrating ideas about invisible playgrounds from play theory into online educational digital games," in Entertainment Computing-ICEC 2004. Springer, 2004, pp. 598601.

[25] T. M. Connolly, E. A. Boyle, E. MacArthur, T. Hainey, and J. M. Boyle, "A systematic literature review of empirical evidence on com- puter games and serious games," Computers \& Education, vol. 59, no. 2, pp. 661-686, 2012.

[26] D. Druckman, R. A. Bjork et al., In the mind's eye: Enhancing human performance. National Academies Press, 1992.

[27] G.-J. Hwang, C.-C. Tsai, S. J. Yang et al., "Criteria, strategies and research issues of context-aware ubiquitous learning." Educational Technology \& Society, vol. 11, no. 2, pp. 81-91, 2008.

[28] C.-M. Chen and Y.-L. Li, "Personalised context-aware ubiquitous learning system for supporting effective english vocabulary learning," Interactive Learning Environments, vol. 18, no. 4, pp. 341-364, 2010.

[29] H. Ogata and Y. Yano, "Knowledge awareness map for computersupported ubiquitous language-learning," in Wireless and Mobile Technologies in Education, 2004. Proceedings. The 2nd IEEE International Workshop on. IEEE, 2004, pp. 19-26.

[30] T. I. Wang, K. H. Tsai, M.-C. Lee, and T. K. Chiu, "Personalized learning objects recommendation based on the semantic-aware discovery and the learner preference pattern," Educational Technology \& Society, vol. 10, no. 3, pp. 84-105, 2007.

[31] C.-M. Chen and Y.-N. Tsai, "Interactive augmented reality system for enhancing library instruction in elementary schools," Computers \& Education, vol. 59, no. 2, pp. 638-652, 2012.

[32] Á. Di Serio, M. B. Ibáñez, and C. D. Kloos, "Impact of an augmented reality system on students' motivation for a visual art course," Computers \& Education, vol. 68, pp. 586-596, 2013.

[33] A. M. Kamarainen, S. Metcalf, T. Grotzer, A. Browne, D. Mazzuca, M. S. Tutwiler, and C. Dede, "Ecomobile: Integrating augmented reality and probeware with environmental education field trips," Computers \& Education, vol. 68, pp. 545-556, 2013.

[34] P.-S. Tsai, C.-C. Tsai, and G.-H. Hwang, "College students conceptions of context-aware ubiquitous learning: A phenomenographic analysis," The Internet and Higher Education, vol. 14, no. 3, pp. 137-141, 2011.

[35] D.-R. Chen, M.-Y. Chen, T.-C. Huang, and W.-P. Hsu, "Developing a mobile learning system in augmented reality context," International Journal of Distributed Sensor Networks, vol. 2013, 2013.

[36] P. Milgram, H. Takemura, A. Utsumi, and F. Kishino, "Augmented reality: A class of displays on the reality-virtuality continuum," in Photonics for Industrial Applications. International Society for Optics and Photonics, 1995, pp. 282-292.

[37] F. Liarokapis, P. Petridis, P. F. Lister, M. White et al., "Multimedia augmented reality interface for e-learning (marie)," World Transactions on Engineering and Technology Education, vol. 1, no. 2, pp. 173-176, 2002.

[38] W. Matcha and D. R. A. Rambli, "Preliminary investigation on the use of augmented reality in collaborative learning," in Informatics Engineering and Information Science. Springer, 2011, pp. 189-198.

[39] R. Benson and G. Samarawickrema, "Addressing the context of e-learning: using transactional distance theory to inform design," Distance Education, vol. 30, no. 1, pp. 5-21, 2009.

[40] M. G. Moore, "Learner autonomy: The second dimension of independent learning," Convergence, vol. 5, no. 2, pp. 76-88, 1972.

[41] P. Gorsky and A. Caspi, "A critical analysis of transactional distance theory," The Quarterly Review of Distance Education, vol. 6, no. 1, pp. 1-11, 2005.

[42] I. R. Katz and A. S. Macklin, "Information and communication technology (ict) literacy: Integration and assessment in higher education,' Journal of Systemics, Cybernetics and informatics, vol. 5, no. 4, pp. $50-55,2007$.

[43] J. I. S. Committee et al., "Higher education in a web 2.0 world: Report of an independent committee of inquiry into the impact on higher education of students' widespread use of web 2.0 technologies," 2009. 